\title{
MicroRNA-379 inhibits metastasis and epithelial-mesenchymal transition via targeting FAK/AKT signaling in gastric cancer
}

\author{
MEIZHONG XU ${ }^{1}$, SHUI QIN ${ }^{1}$, FAN CAO $^{2}$, SHI DING $^{1}$ and MENGNAN LI ${ }^{2}$ \\ ${ }^{1}$ Forensic Surgery, and ${ }^{2}$ Department of Gastroenterology, The Traditional Chinese \\ Medicine Hospital of Jingshan County, Jingshan, Hubei 431800, P.R. China
}

Received January 2, 2017; Accepted July 4, 2017

DOI: $10.3892 /$ ijo.2017.4072

\begin{abstract}
Accumulating evidence demonstrates that aberrant miRNAs contribute to gastric cancer (GC) development and progression. However, the roles of various miRNAs in GC remain to be determined. In the present study, we confirmed that a reduced miR-379 expression was present in GC tissues and cell lines. Our clinical analysis revealed that the downregulated miR-379 expression was significantly correlated with poor prognostic features including lymph node metastasis and advanced TNM stage. Moreover, we confirmed that miR-379 was a novel independent prognostic marker for predicting 5-year survival of GC patients. The ectopic overexpression of miR-379 inhibited cell migration, invasion and EMT progress, while downregulated miR-379 reversed the effect. In addition, miR-379 regulated the focal adhesion kinase (FAK) by directly binding to its 3'-UTR, resulting in suppression of AKT signaling. In clinical samples of GC, miR-379 inversely correlated with FAK, which was upregulated in GC. Alteration of FAK expression or activating AKT signaling at least partially abolished the migration, invasion and EMT progress effects of miR-379 on GC cells. In conclusion, our results indicated that miR-379 functioned as a tumor suppressor gene in regulating the EMT and metastasis of GC via targeting FAK/AKT signaling, and may represent a novel potential therapeutic target and prognostic marker for GC.
\end{abstract}

\section{Introduction}

Gastric cancer (GC) is one of the most common types of cancer worldwide and the second leading cause of cancer-related death globally $(1,2)$. Despite remarkable advance in diagnostic techniques, such as endoscopic detection, and improvement in therapeutic modalities (3), including novel chemotherapeutic

Correspondence to: Professor Mengnan Li, Department of Gastroenterology, The Traditional Chinese Medicine Hospital of Jingshan County, No. 26 Yanhe South Road, Jingshan, Hubei 431800, P.R. China

E-mail:1imn1022@sina.com

Key words: microRNA-379, gastric cancer, focal adhesion kinase, epithelial-to-mesenchymal transition, invasion interventions and target therapy, the long-term survival of GC patients remains unsatisfactory due to the high rates of local invasion and distal metastasis (4). Therefore, it is critical to identify the potential molecular mechanisms underlying the progression and metastasis in GC and thus, provide novel therapeutic targets for cancer treatment (5).

MicroRNAs (miRNAs) are a group of endogenous and conserved non-coding RNAs that modulate the specific protein expression through binding to the 3'-untranslated region (3'-UTR) of target mRNAs based on sequence complementarity, and function as post-transcriptional regulators of gene expression (6,7). Increasing evidence has confirmed that miRNAs are abnormally expressed in various cancers, including GC (8), and participate in different biological progress including cell growth, apoptosis, differentiation and metastasis $(9,10)$. Therefore, miRNAs have been proposed as promising prognostic markers for GC patients (11).

Among numerous cancer-related miRNAs, miR-379, which is located on chromosome $14 \mathrm{q} 32.31$, was recently found to be a novel cancer-related miRNA $(12,13)$. It was downregulated in breast cancer $(12,14)$, glioblastoma (15), hepatocellular carcinoma (16) and malignant pleural mesothelioma (17). miR-379 was decreased in breast cancer and inhibited cell proliferation by regulating cyclin B1 expression (12). miR-379 regulated IL-18 and contributed to drug resistance in malignant pleural mesothelioma (17). However, in prostate cancer (13) and papillary renal cell carcinoma (18), miR-379 was found to be upregulated. Elevated miR-379 in prostate cancer facilitated tumor growth, epithelial to mesenchymal transition (EMT) and bone metastasis. Therefore, the functional significance of miR-379 in cancer development and progression seem to be cancer-type specific. However, the expression and functional role of miR-379 in GC have not been elucidated before.

Epithelial-to-mesenchymal transition (EMT) has been recognized as a physiological process in the invasion and metastasis of various cancers through transformation of adherent and polarized epithelial cells into an invasive mesenchymal cell phenotype (19-21). Moreover, cancer cells undergoing the EMT usually decreased the cell adhesion molecule E-cadherin, which is an important determinant of epithelial cell-cell adhesion, while increased the vimentin and $\mathrm{N}$-cadherin expression (22). Accumulating evidence has revealed that EMT can mediate both GC invasion and metas- 
tasis (23-25). However, the association between miR-379 and EMT in GC has remained elusive.

In the present study, we investigated the effects of miR-379 on the FAK/AKT signaling in GC cells. Our data showed that miR-379 was downregulated in the GC and the reduced miR-379 was associated with poor prognostic features and poor 5-year survival of GC patients. We also confirmed that miR-379 could regulate the migration, invasion and EMT phenotype of GC by targeting FAK/AKT signaling in vitro and in vivo. These data identify the underlying mechanism by which miR-379 inhibits migration and invasion of GC and indicates miR-379 as a novel prognostic biomarker for GC patients.

\section{Materials and methods}

Clinical specimens. Ninety-six GC tissues and paired adjacent non-cancerous tissues were obtained from the Traditional Chinese Medicine Hospital of Jingshan County during January 2005 to December 2010. Pathological diagnosis was performed according to the World Health Organization (WHO) criteria. None of the patients received chemotherapy or radiotherapy before surgery. All patients gave written informed consent and this study was approved by the Ethics Committee of the Traditional Chinese Medicine Hospital of Jingshan County.

The human GC cell lines SGC7901, MGC803, HGC27, MKN45 and the normal gastric epithelial cell line GES-1 were obtained from the Institute of Biochemistry and Cell Biology (Chinese Academy of Sciences, Shanghai, China) and were cultured in RPMI-1640 medium (Invitrogen, Carlsbad, CA, USA) containing $10 \%$ fetal bovine serum (FBS; Invitrogen), $1 \%$ penicillin-streptomycin (Sigma-Aldrich, St. Louis, MO, USA) in a humidified atmosphere at $37^{\circ}$ with $5 \% \mathrm{CO}_{2}$.

Quantitative reverse transcriptase polymerase chain reaction ( $q R T-P C R)$. Total RNA from GC tissues and cells was isolated using TRIzol reagent (Invitrogen) according to the manufacturer's protocol. cDNA was reverse-transcribed from $1 \mu \mathrm{g}$ total RNA using a Reverse Transcription kit (Takara Bio, Shiga, Japan). cDNA was then amplified with a SYBR ${ }^{\circledR}$ Premix Ex Taq ${ }^{\mathrm{TM}}$ II (Perfect real-time) kit (Takara Bio). The gene expression levels were calculated using the $\Delta \Delta \mathrm{Ct}$ method with U6 or GAPDH as an internal control. Hsa-miR-379 primer (HmiRQP0476), snRNA U6 qPCR Primer (HmiRQP9001), FAK (HQP015639) and GAPDH (HQP006940) were purchased from GeneCopoeia (Guangzhou, China).

Cell transfection. miRNA vectors, including miR-379 expression vector (HmiR0219), the control vector for miR-374 (CmiR0001), miR-379 inhibitor (HmiR-AN0476) and the negative control (CmiR-AN0001-AM04) were obtained from GeneCopoeia. The FAK overexpression plasmid and specific siRNA against FAK and a scramble siRNA were synthesized by Sangon Biotech, Co., Ltd. (Shanghai, China). Cells were transfected with above vectors using Lipofectamine 2000 reagent (Invitrogen/Life Technologies) in accordance with the manufacturer's protocol.

Western blot analysis. The whole proteins were harvested in RIPA buffer supplemented with protease and phosphatase inhibitors (Roche) and the concentrations were quantified with BCA protein assay kit (Tiangen Biotech, Co., Ltd., Beijing, China), and an equal amount of $30 \mu \mathrm{g}$ protein was separated by $10 \%$ SDS-PAGE gel and then transferred onto PVDF membranes (Millipore, Billerica, MA, USA). The membranes were blocked with 5\% non-fat milk in TBST for $2 \mathrm{~h}$ at room temperature and incubated overnight with specific primary antibodies (1:1,000; Cell Signaling Technology, Inc., Danvers, MA, USA) at $4^{\circ} \mathrm{C}$. Then the membranes were washed three times by TBST and incubated with HRP-conjugated secondary antibody for $2 \mathrm{~h}$ at room temperature (SGB-Bio, Beijing, China). Detection was performed by enhanced chemiluminescence kit (Amersham, Little Chalfont, UK). GAPDH was used as protein loading control. The antibodies against FAK, E-cadherin, N-cadherin, vimentin, AKT and p-AKT were purchased from Cell Signaling Technology.

Immunohistochemical staining (IHC). Briefly, $4 \mu \mathrm{m}$ sections were deparaffinized in xylene, rehydrated through graded ethanols, followed by blocking of endogenous peroxidase activity in $3 \%$ hydrogen peroxide for $10 \mathrm{~min}$ at room temperature. The corresponding antibody (1:300; Cell Signaling Technology) was applied as the primary antibody by a streptavidin peroxidase-conjugated (SP-IHC) method. The staining results were semi-quantitatively evaluated by the multiply of staining intensity and the percentage of positive staining cells. The percentage of positive cells was given into four grades: 0 for $<5 \%$; 1 for $6-25 \% ; 2$ for $26-50 \% ; 3$ for $51-75 \%$ and 4 for $>75 \%$. Staining intensity was assessed by four degrees: 0 , negative; 1 , weak; 2 , moderate; and 3, strong. Each section was assayed for ten independent high magnification (x400) fields to get the average scores.

Cell migration and invasion analyses. Matrigel-uncoated and -coated Transwell inserts ( $8 \mu \mathrm{m}$ pore size; Millipore) were used to evaluate cell migration and invasion. Briefly, $2 \times 10^{4}$ transfected cells were suspended in $150 \mu \mathrm{l}$ serum-free RPMI1640 medium into the upper chamber, and $700 \mu$ R RMI-1640 medium containing $20 \%$ FBS was placed in the lower chamber. After 24-h incubation, cells were fixed in 4\% paraformaldehyde for $20 \mathrm{~min}$ and stained with $0.1 \%$ crystal violet dye for $15 \mathrm{~min}$. The cells on the inner layer were softly removed with a cotton swab and counted at five randomly selected views, and the average cell number per view was calculated.

Luciferase reporter assay. The 3'-UTR sequence of FAK predicted to interact with $\mathrm{miR}-379$, together with a corresponding mutated sequence within the predicted target sites, were synthesized and inserted into the pmiR-GLO Dual-luciferase miRNA target expression vector (Promega, Madison, WI, USA) called wt-FAK 3'-UTR and mt-FAK 3'-UTR. Subsequently, MGC803 cells that were plated into 24-well plate and were transfected with miR-379 inhibitor or negative control. Cells were co-transfected with the wild-type or mutant 3'-UTR of FAK vector using the Lipofectamine 2000 reagent (Invitrogen). After $48 \mathrm{~h}$, cells were harvested and measured according to the manufacturer's instructions (Dual-luciferase assay system; Promega). pRL-TK expressing Renilla luciferase was cotransfected as an internal control to correct the differences in both transfection and harvest efficiencies. 
Table I. The relationship between miR-379 expression and clinicopathological features in GC patients $(\mathrm{n}=96)$.

\begin{tabular}{|c|c|c|c|c|}
\hline \multirow[b]{2}{*}{$\begin{array}{l}\text { Clinical } \\
\text { parameters }\end{array}$} & \multirow[b]{2}{*}{$\begin{array}{l}\text { Cases } \\
\text { (n) }\end{array}$} & \multicolumn{2}{|c|}{ Expression level } & \multirow[b]{2}{*}{ P-value } \\
\hline & & $\begin{array}{l}\operatorname{miR}-379^{\text {high }} \\
\quad(\mathrm{n}=44)\end{array}$ & $\begin{array}{c}\mathrm{miR}-379^{\text {low }} \\
\quad(\mathrm{n}=52)\end{array}$ & \\
\hline Age (years) & & & & 0.986 \\
\hline$<60$ & 35 & 16 & 19 & \\
\hline$\geq 60$ & 61 & 28 & 33 & \\
\hline Sex & & & & 0.439 \\
\hline Male & 66 & 32 & 34 & \\
\hline Female & 30 & 12 & 18 & \\
\hline Tumor size $(\mathrm{cm})$ & & & & 0.156 \\
\hline$<5$ & 72 & 36 & 36 & \\
\hline$\geq 5$ & 24 & 8 & 16 & \\
\hline Histological type & & & & 0.238 \\
\hline Intestinal & 78 & 38 & 40 & \\
\hline Diffuse & 18 & 6 & 12 & \\
\hline TNM stage & & & & $<0.001^{\mathrm{a}}$ \\
\hline I+II & 40 & 28 & 12 & \\
\hline III+IV & 56 & 16 & 40 & \\
\hline Lymph metastasis & & & & $<0.001^{\mathrm{a}}$ \\
\hline Present & 58 & 18 & 40 & \\
\hline Absent & 38 & 26 & 12 & \\
\hline
\end{tabular}

${ }^{\mathrm{a}} \mathrm{P}<0.05$ statistically significant.

Statistical analysis. Data are presented as the mean \pm SD and performed at least three independent replicates. SPSS software, 16.0 (SPSS, Inc., Chicago, IL, USA) and Graphpad Prism 6.0 (GraphPad Software, Inc., La Jolla, CA, USA) were used for a two-tailed Student's t-test, Pearson's correlation analysis, Kaplan-Meier method and the log-rank test to evaluate the statistical significance. Differences were defined as $\mathrm{P}<0.05$.

\section{Results}

The expression of miR-379 is decreased in gastric cancer tissues and cell lines. To investigate whether miR-379 was involved in gastric carcinogenesis, we first examined the expression of miR-379 in 96 pairs of GC tissues and the paired normal gastric mucosa. Our results showed that miR-379 expression in GC tissues was significantly downregulated compared with the paired non-cancerous tissues $(\mathrm{P}<0.01$; Fig. 1A). Moreover, similar result was found in GC cell lines. The data revealed that miR-379 was remarkably reduced in a panel of GC cell lines compared to the normal gastric epithelial cell line GES-1 ( $<<0.05$; Fig. 1B). These results confirmed that miR-379 was downregulated in gastric cancer tissues and cell lines.

Clinical significance of the downregulated miR-379 expression in GC tissues. To further investigate the role of miR-379 in the progression of GC, we determined the relationship between
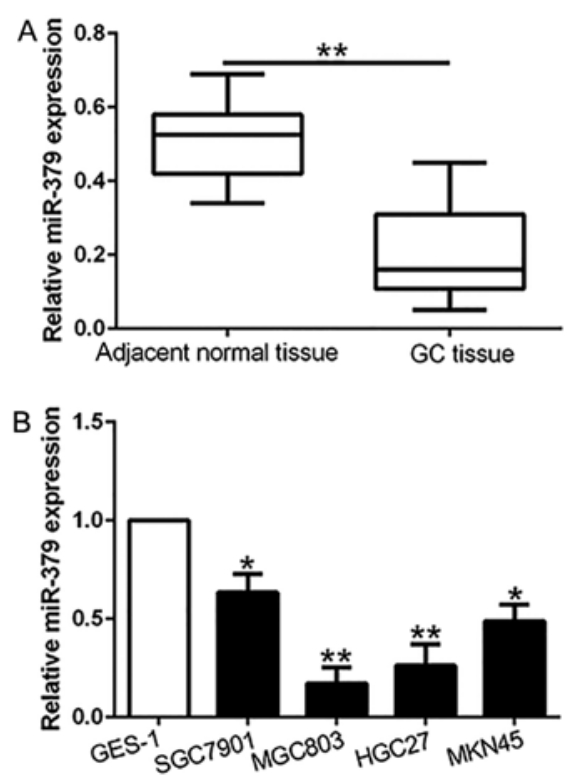

Figure 1.Expression of miR-379 in GC tissues and cell lines.(A) Quantification of the data revealed that the mean level of miR-379 expression in GC tissues was significantly lower than that in matched adjacent non-cancer tissues. (B) Comparing differences in the expression levels of miR-379 between GC cell lines compared to the normal gastric epithelial cell line (GES-1). n, six repeats with similar results. U6 snRNA was used as internal control. ${ }^{*} \mathrm{P}<0.05$, ${ }^{* *} \mathrm{P}<0.01$.
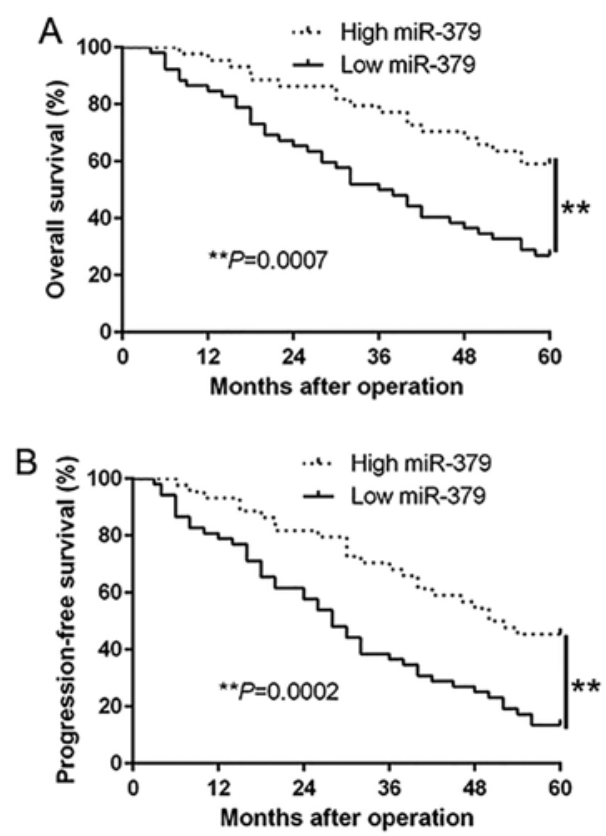

Figure 2. The prognostic value of miR-379 for GC patients. GC patients with lower expression of miR-379 had worse (A) overall survival and (B) progression-free survival. ${ }^{* *} \mathrm{P}<0.01$.

miR-379 expression and the clinicopathological features and prognosis of GC patients. With the median level of miR-379 as the cut-off, the low miR-379 expression was obviously associated with lymph node metastasis $(\mathrm{P}<0.001)$ and advanced TNM stage $(\mathrm{P}<0.001)($ Table I). Moreover, Kaplan-Meier analysis revealed that the downregulation of miR-379 was prominently correlated with shorter overall survival $(\mathrm{P}=0.0007$; Fig. $2 \mathrm{~A})$ and shorter progression-free survival $(\mathrm{P}=0.0002$; Fig. $2 \mathrm{~B})$ 
Table II. Multivariate Cox regression analysis of 5-year OS and PFS of 96 GC patients.

\begin{tabular}{|c|c|c|c|c|c|c|}
\hline \multirow[b]{2}{*}{ Variables } & \multicolumn{3}{|c|}{ Overall survival } & \multicolumn{3}{|c|}{ Progression-free survival } \\
\hline & HR & $95 \%$ CI & P-value & HR & $95 \% \mathrm{CI}$ & P-value \\
\hline miR-379 expression & 0.212 & $0.056-0.892$ & $0.012^{\mathrm{a}}$ & 0.232 & $0.072-0.726$ & $0.014^{\mathrm{a}}$ \\
\hline TNM stage & 2.563 & $1.317-5.982$ & $0.007^{\mathrm{a}}$ & 2.223 & $1.113-4.889$ & $0.009^{\mathrm{a}}$ \\
\hline Lymph metastasis & 3.243 & $1.572-6.238$ & $0.003^{\mathrm{a}}$ & 3.027 & $1.476-6.193$ & $0.004^{\mathrm{a}}$ \\
\hline
\end{tabular}

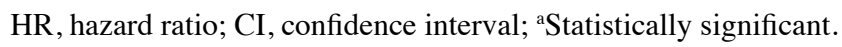

A

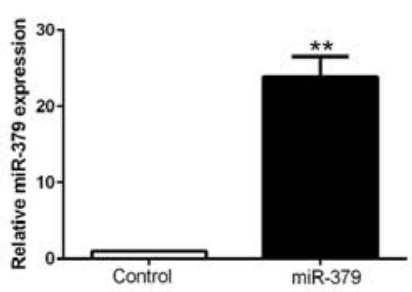

C

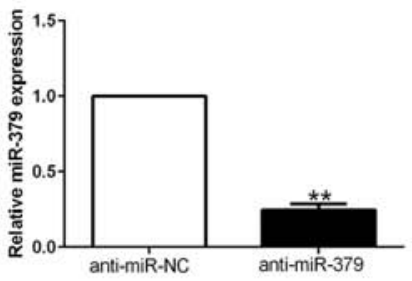

B

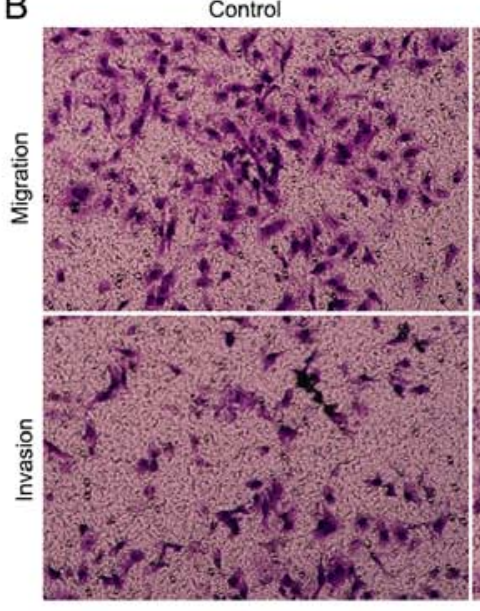

anti-miR-NC

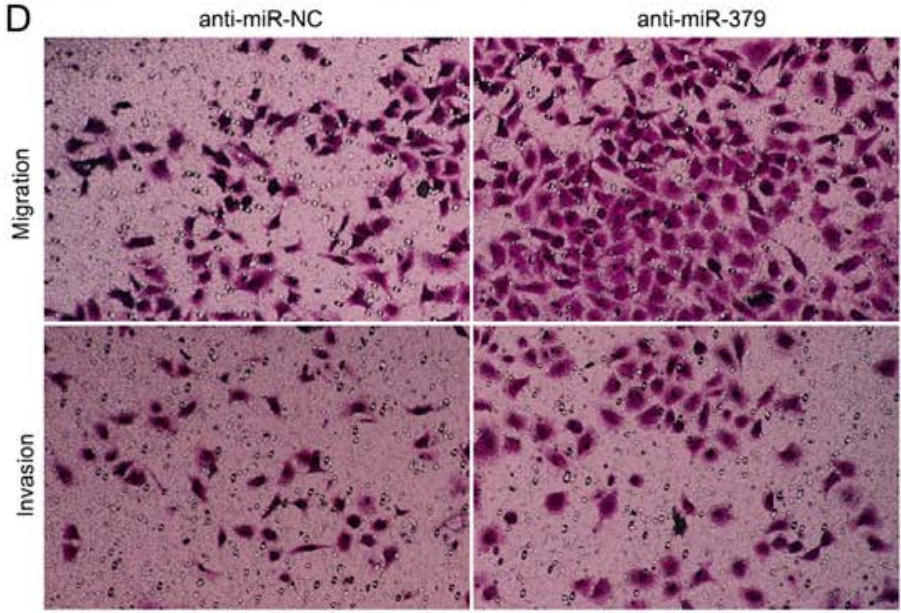

$\operatorname{miR}-379$
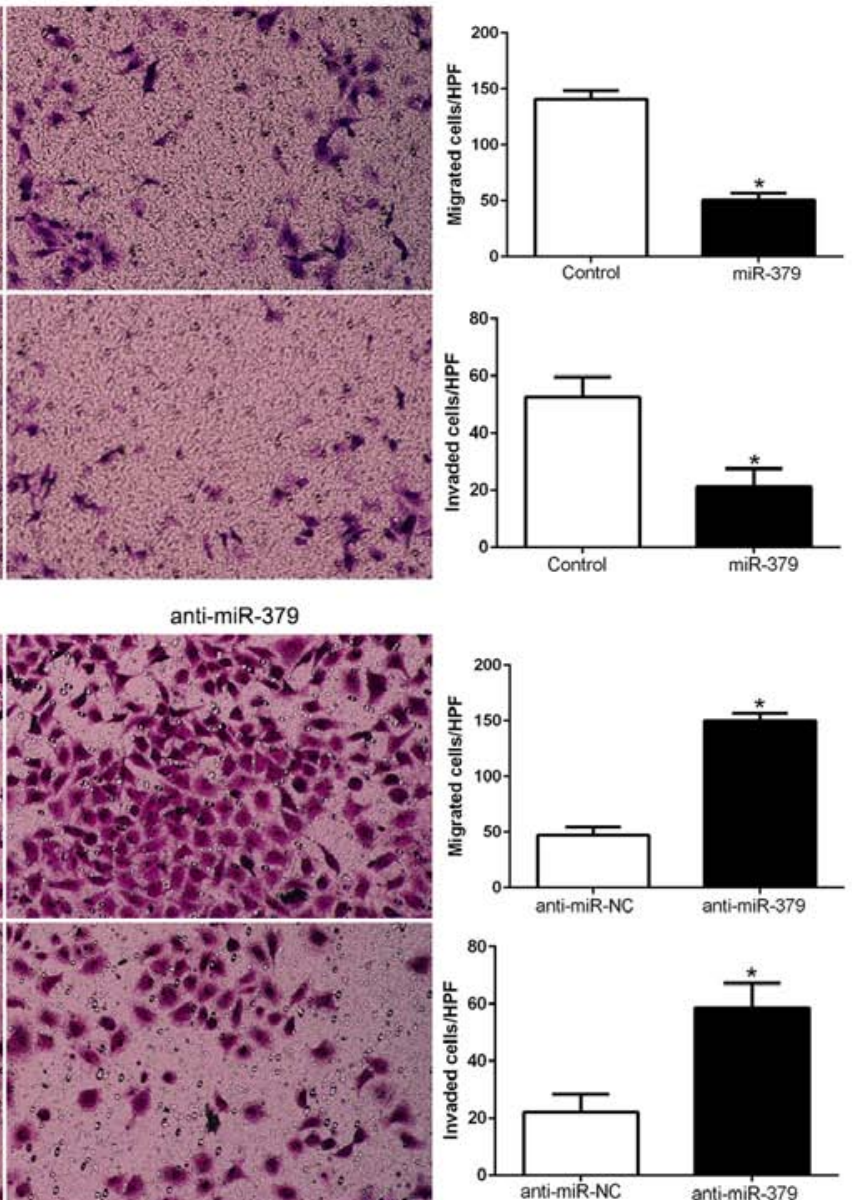

Figure 3. miR-379 inhibits GC cell migration and invasion in vitro. (A) MGC803 cells that were transfected with corresponding miRNA vectors were subjected to qRT-PCR for miR-379. (B) Cell migration and invasion as measured by Transwell assays were inhibited by overexpression of miR-379 in MGC803 cells. (C) SGC7901 cells that were transfected with miR-379 inhibitors (anti-miR-379) and negative control were subjected to qRT-PCR for miR-379. (D) Cell migration and invasion as measured by Transwell assays were increased by knockdown of miR-379 in SGC7901 cells. $\mathrm{n}$, six independent experiments. ${ }^{*} \mathrm{P}<0.05,{ }^{* *} \mathrm{P}<0.01$.

in GC patients. Furthermore, miR-379 expression was an independent factor for predicting both 5-year overall and progression-free survival in $\mathrm{GC}$ patients $(\mathrm{P}=0.012, \mathrm{P}=0.014$, respectively; Table II). These results indicate that miR-379 may act as a potent biomarker for predicting prognosis of GC patients.

miR-379 inhibits GC cell migration and invasion. To explore the biological function of miR-379 in HCC, we transduced GC cell lines with miR-379 expression vector or anti-miR-379 vector which contained different endogenous miR-379 levels. As determined by qRT-PCR, we confirmed that miR-379 effectively upregulated miR-379 in MGC803 $(\mathrm{P}<0.05$; Fig. 3A) or downregulated miR-379 in SGC7901 cells $(\mathrm{P}<0.05$; Fig. 3C). As examined by Matrigel-coated (for invasion) and -uncoated (for migration) Transwell assays, miR-379 overexpression significantly inhibited the migration and invasion of MGC803 cells ( $\mathrm{P}<0.05$; Fig. 3B), whereas 


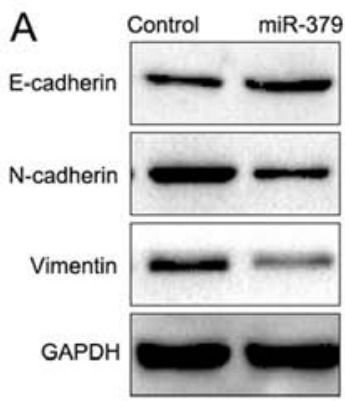

C a

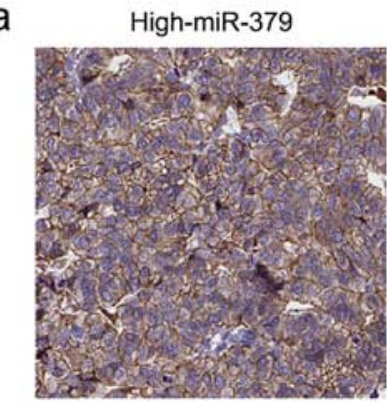

C

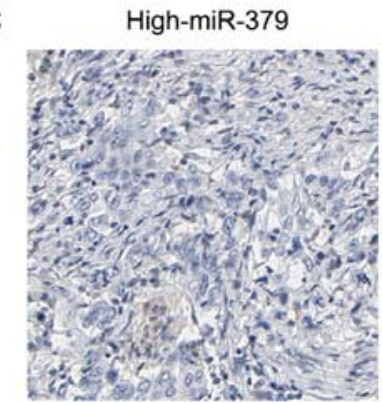

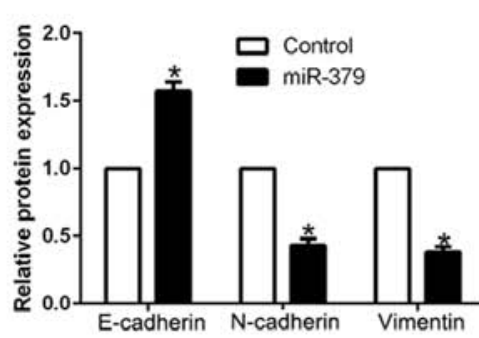

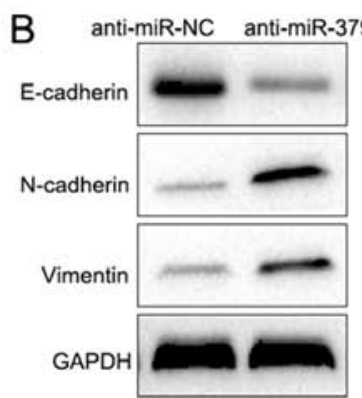

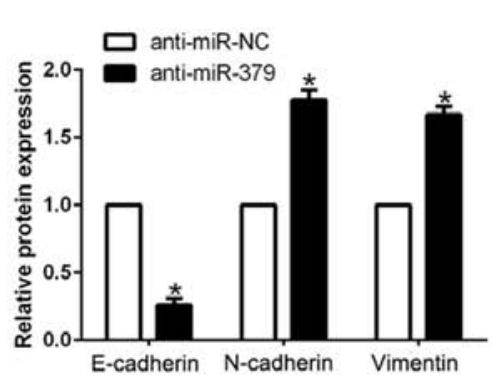

b
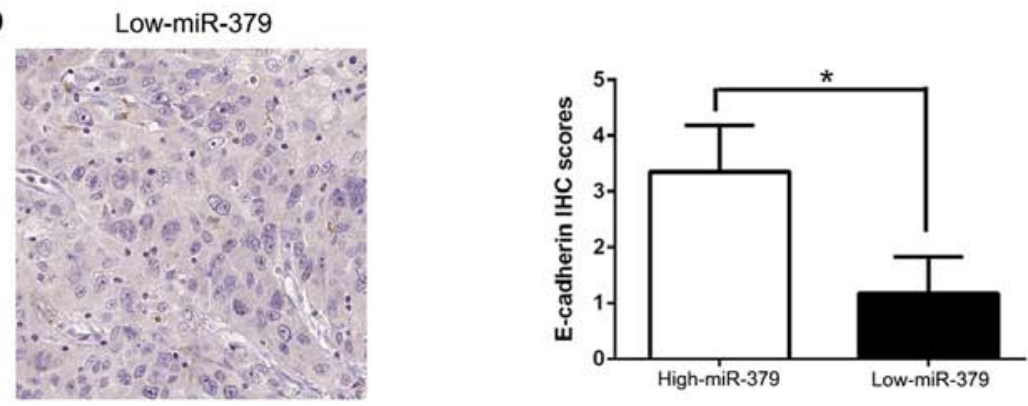

d
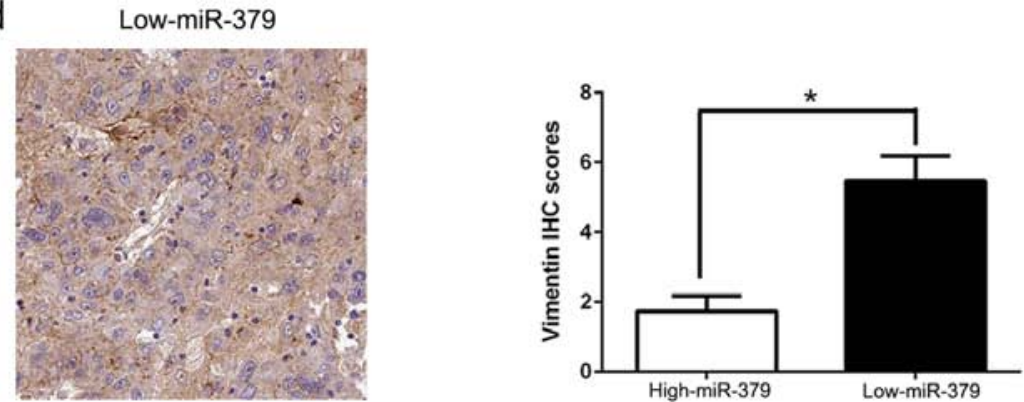

Figure 4. miR-379 suppresses epithelial-to-mesenchymal transition in GC cells. The overexpression of miR-379 in MGC803 cells increased the expression of the epithelial cell marker E-cadherin and decreased the expression of the mesenchymal cell markers N-cadherin and vimentin (A). In contrast, the expression of the antagomiR to miR-379 decreased E-cadherin expression and increased N-cadherin and vimentin expression (B). Immunohistochemical analysis of E-cadherin and vimentin in GC samples (C). In cases of high miR-379 expression (a and c); there was strong E-cadherin (a) and no detectable vimentin protein (c) expression in the same tissue section. In contrast, in the case of low miR-379 expression (b and d), there was no detectable E-cadherin (b) and strong vimentin protein (d) expression. Values are depicted as mean $\pm \mathrm{SEM}$; ${ }^{*} \mathrm{P}<0.05$ by $\mathrm{t}$-test.

miR-379 knockdown obviously increased the number of migrated and invaded SGC7901 cells (P<0.05; Fig. 3D). In conclusion, these data suggested that miR-379 could regulate the GC cell migration and invasion and may exert an antimetastatic effect on GC.

miR-379 suppresses epithelial-to-mesenchymal transition in $G C$ cells. EMT has been proposed as a critical role in the initiation of metastasis progression of cancer. To gain a mechanistic illustration of the potential role of miR-379 in modulating GC metastasis, the EMT markers were measured. We found that miR-379 overexpression facilitated the epithelial marker E-cadherin and suppressed $\mathrm{N}$-cadherin and vimentin expression ( $\mathrm{P}<0.05$; Fig. 4A). In contrast, miR-379 knockdown decreased E-cadherin expression and increased $\mathrm{N}$-cadherin and vimentin expression $(\mathrm{P}<0.05$; Fig. 4B). In addition, we further explored the correlation between miR-379 expression and EMT marker in GC tissues. We found that the E-cadherin expression in high miR-379 group was higher than that in low miR-379 group. Conversely, the expression level of vimentin in the high miR-379 group was markedly lower than that in low miR-379 group ( $\mathrm{P}<0.05$; Fig. 4C). Taken together, these results suggest that miR-379 function as a suppressor of EMT in GC cells.

FAK is a direct downstream target of miR-379 in GC cells. To elucidate the molecular mechanisms responsible for the functional influence of miR-379 in GC cells, we searched the publically available database TargetScan to explore the candidate target genes. Among them, FAK was known to play an important role in GC invasion and metastasis (26). As shown in Fig. 5A, the sequence complementary to the binding sites of miR-379 was revealed in the 3'-UTR of FAK. We performed a luciferase reporter assay to verify that miR-379 could bind to the 3'-UTR of FAK. The results showed that miR-379 overexpression significantly decreased the luciferase activity of wild-type (wt) FAK 3'-UTR while had no influence on that of mutant (mt) FAK 3'-UTR $(\mathrm{P}<0.05$; Fig. 5B). On the contrary, miR-379 knockdown increased the luciferase activity of wt FAK 3'-UTR ( $\mathrm{P}<0.05$; Fig. 5B) but did not affect the luciferase activity of mt FAK 3'-UTR constructs. In addition, miR-379 overexpression markedly reduced the mRNA and protein levels of FAK in MGC803 cells $(\mathrm{P}<0.05$, respectively; Fig. $5 \mathrm{C}$ and $\mathrm{D})$. By contrast, the 
A

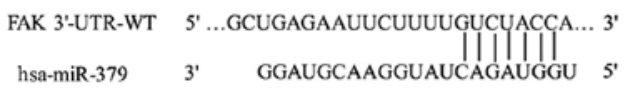

FAK 3'-UTR-MT 5 '...GCUGagaAuUCUUUUCAGAUUAU... 3'
B

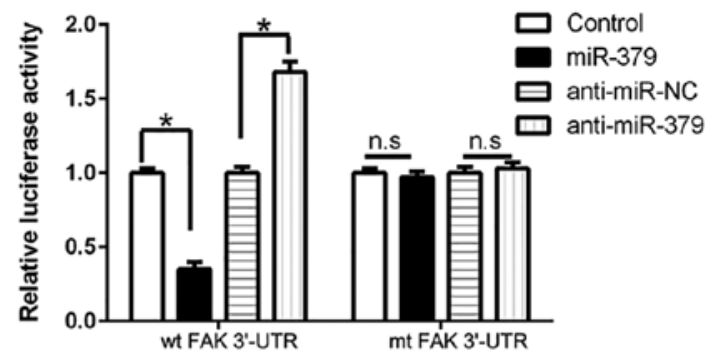

C
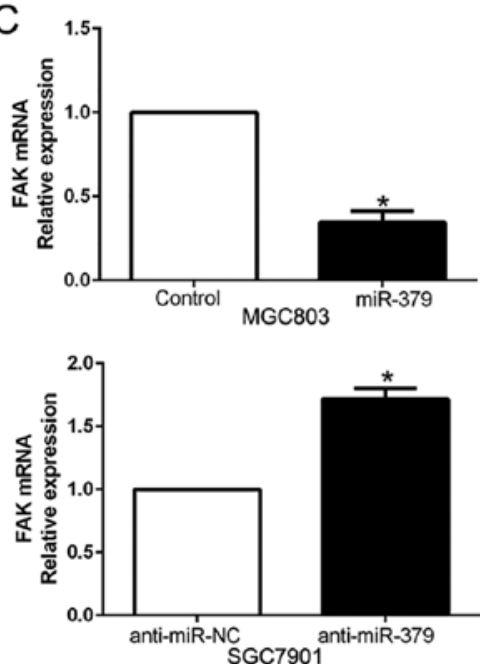

D
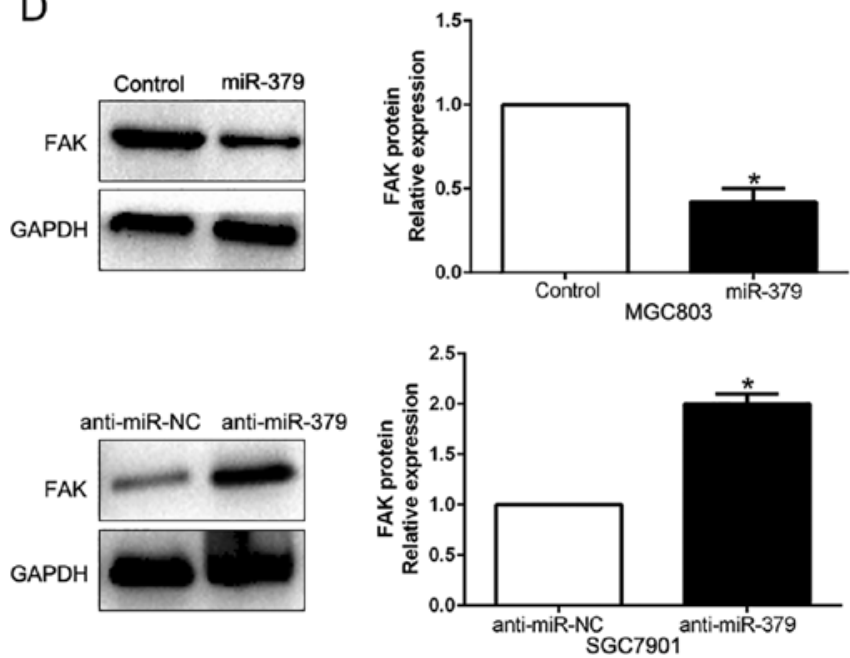

Figure 5. FAK is identified as a direct target of miR-379 in GC. (A) miR-379 and its putative binding sequence in the 3'-UTR of FAK. The mutant binding site was generated in the complementary site for the seed region of miR-379. (B) miR-379 significantly suppresses the luciferase activity that carried wild-type (wt) but not mutant (mt) 3'-UTR of FAK. Anti-miR-379 led to a notable increase in the luciferase activity of wt 3'-UTR of FAK. (C) qRT-PCR analysis of FAK mRNA expression in MGC803 cells with miR-379 or miR-control vector transfection and SGC7901 cells with anti-miR-379 or anti-miR-NC vector transfection. (D) Overexpression of miR-379 reduced the expression of FAK protein in MGC803 cells and knockdown of miR-379 increases the level of FAK protein in SGC7901 cells. $\mathrm{n}$, six repeats with similar results, ${ }^{*} \mathrm{P}<0.05$.

A

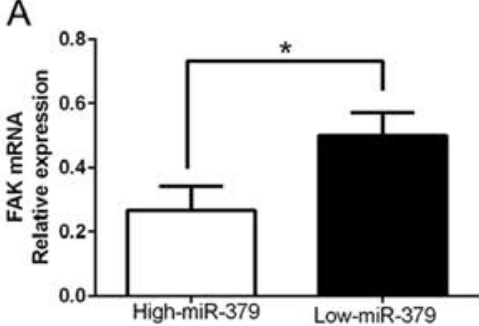

C

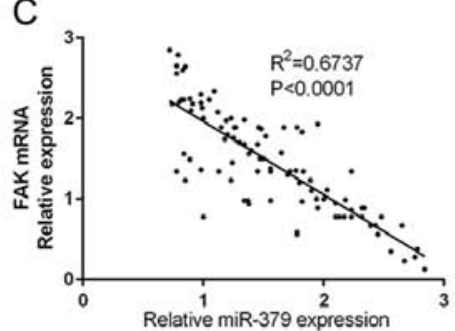

B

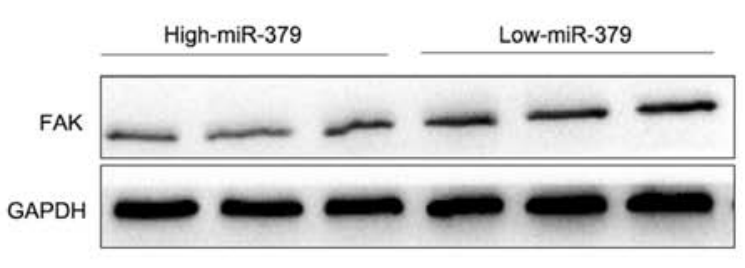

High-miR-379

D

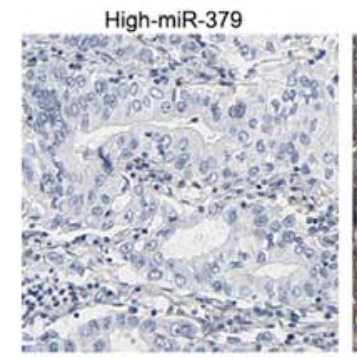

Low-miR-379

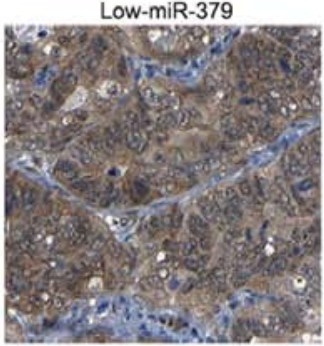

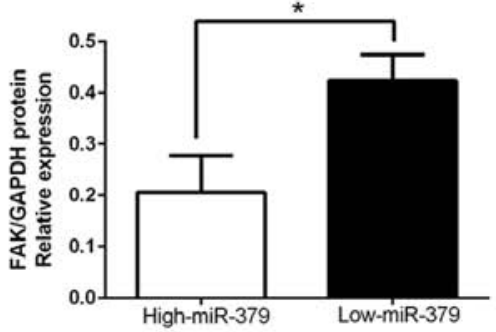

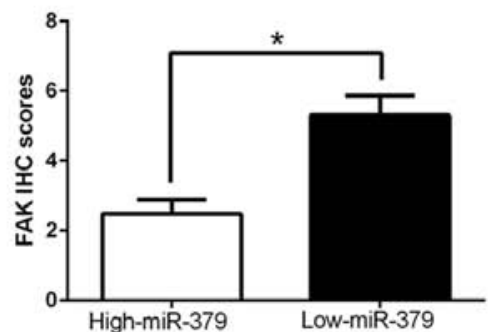

Figure 6. An inverse correlation between miR-379 and FAK expression is observed in GC. (A) The expression of FAK mRNA in miR-379 high-expressing tumors was significantly lower than that in miR-379 low-expressing tumors. (B) The expression of FAK protein in miR-379 high-expressing tumors was significantly lower than that in miR-379 low-expressing tumors. (C) A significant inverse correlation between the mRNA levels of FAK and miR-379 was observed in GC tissues. (D) Representative immunohistochemical staining showed a weak staining of FAK in miR-379 high-expressing GC tissue and strong staining of FAK in the miR-379 low-expressing tumor. ${ }^{*} \mathrm{P}<0.05$.

expression of FAK mRNA and protein were significantly increased by the downregulation of miR-379 in SGC7901 cells $(\mathrm{P}<0.05$, respectively; Fig. 5C and D).
miR-379 correlates negatively with the FAK expression in GC samples. To further evaluate the relationship between miR-379 and FAK in GC tissues, we measured the FAK mRNA and 
A
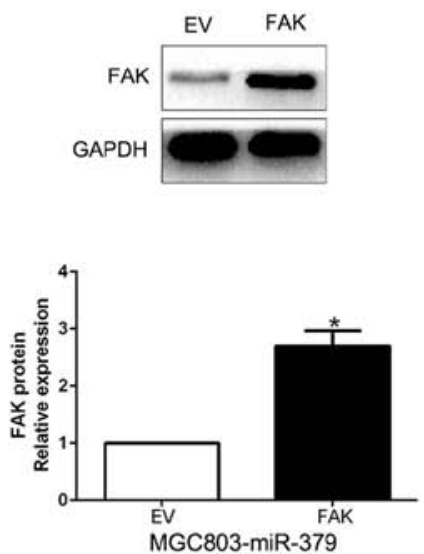

C

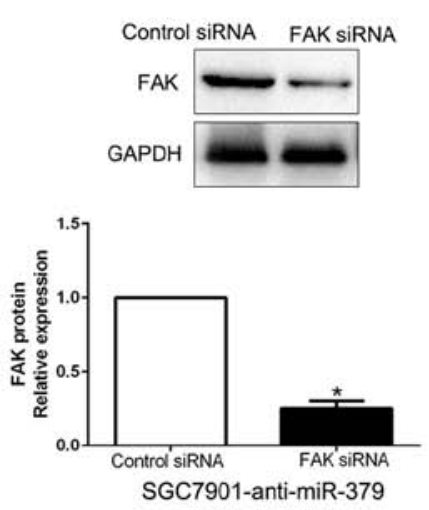

$\mathrm{E}$

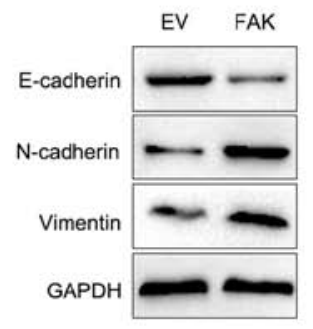

B
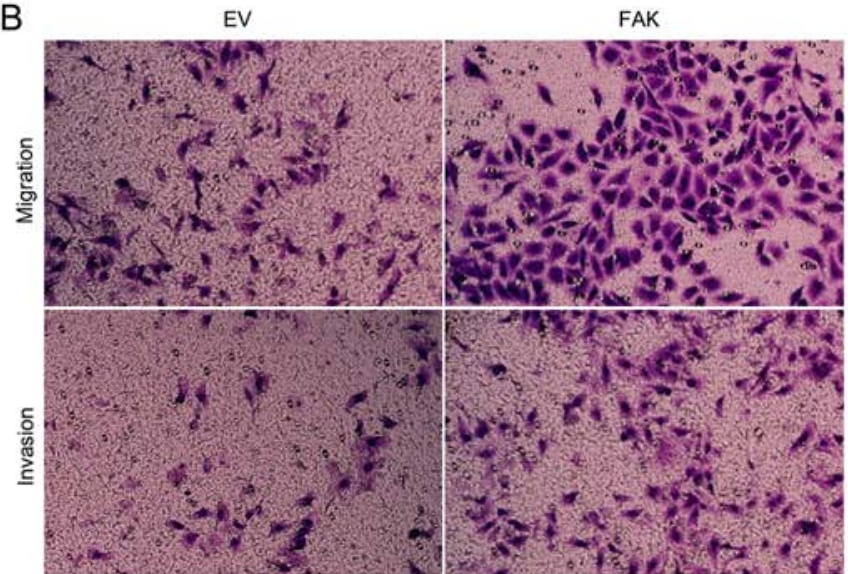

D

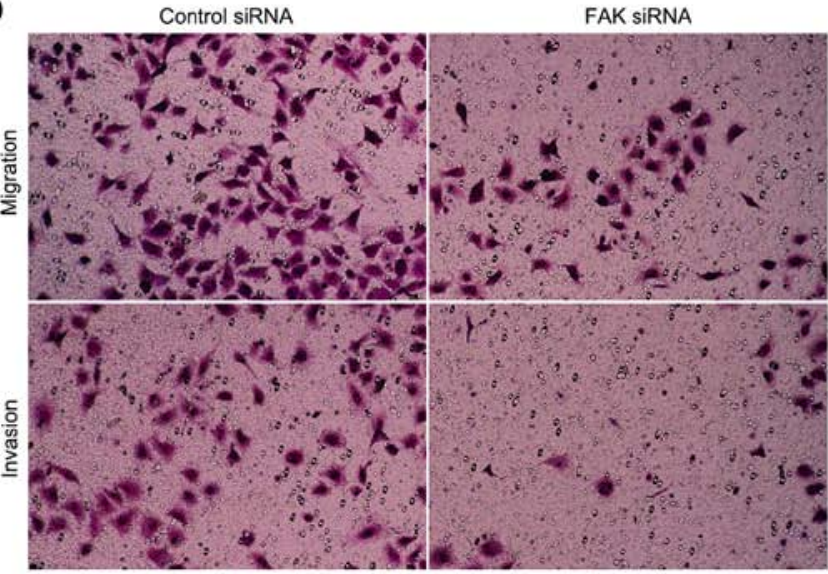

F Control siRnA FAK siRNA

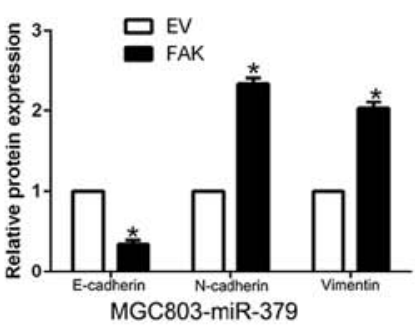

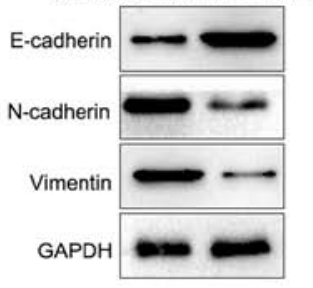

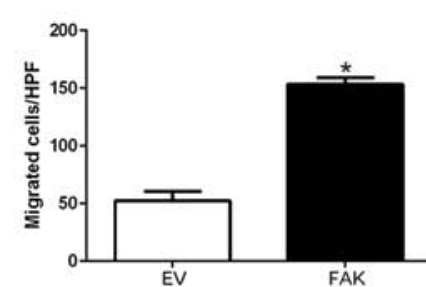

MGC803-miR-379

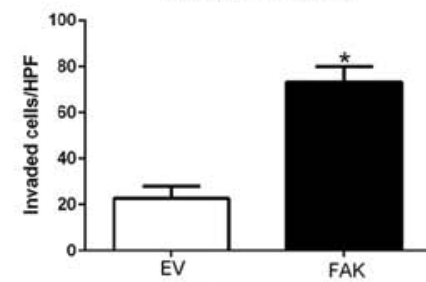

MGC803-miR-379

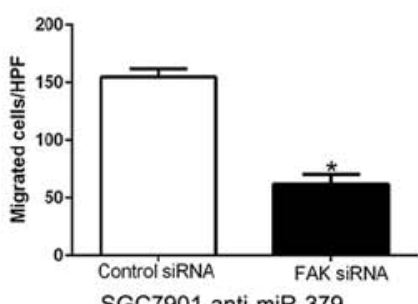

SGC7901-anti-miR-379

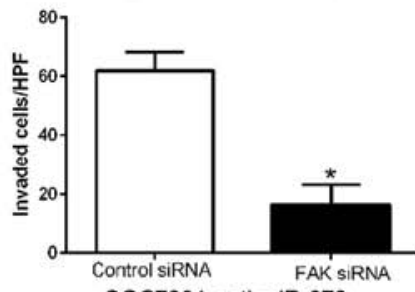

SGC7901-anti-miR-379

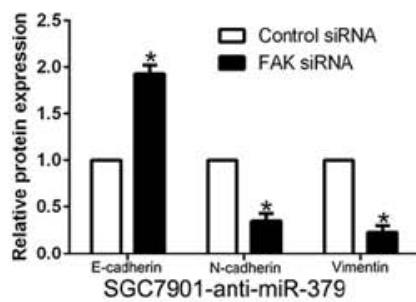

Figure 7. Alterations of FAK partially abolish miR-379-mediated GC cell migration, invasion and EMT progress. (A) miR-379-overexpressing MGC803 cells that were transfected with EV or FAK expression plasmid were subjected to western blot analysis for FAK. (B) Cell migration and invasion of the miR-379-overexpressing MGC803 cells was increased by FAK overexpression. (C) miR-379-suppressive SGC7901 cells that were transfected with scrambled siRNA or FAK siRNA were subjected to western blot analysis for FAK. (D) FAK knockdown abrogated the effects of miR-379 knockdown on SGC7901 cells. (E) Western blot analysis of EMT marker proteins in MGC803 cells stably expressing miR-379 transduced with FAK or control vector. (F) Western blot analysis of indicated proteins in SGC7901 cells stably expressing miR-379 inhibitor transfected with FAK siRNA or control siRNA. n, six independent experiments. EV, empty vector. ${ }^{*} \mathrm{P}<0.05$.

protein expression in two groups of miR-379. As expected, our data showed that both FAK mRNA and protein expression level in high miR-379 group were significantly lower than that in low miR-379 group in GC $(\mathrm{P}<0.05$; Fig. 6A and $\mathrm{B})$. Moreover, we demonstrated that the mRNA level of FAK in the GC tissues was inversely correlated with miR-379 expression $\left(\mathrm{R}^{2}=0.6737, \mathrm{P}<0.0001\right.$; Fig. 6C). Consistently, as assessed by IHC assay, FAK protein expression in miR-379 high-expressing tumors was obviously lower than miR-379 low-expressing tumors $(\mathrm{P}<0.05$; Fig. $6 \mathrm{D})$, which was similar with previous studies. In conclusion, these data suggest that FAK was a direct downstream target of miR-379 in GC.
FAK is essential for the miR-379-mediated inhibition of cell migration, invasion and EMT in HCC cells. To clarify that FAK is a functional target of miR-379, FAK was overexpressed by a plasmid vector in miR-379-overexpressing MGC803 cells ( $\mathrm{P}<0.05$; Fig. 7A). Furthermore, FAK overexpression increased cell migration, and invasion $(\mathrm{P}<0.05$, respectively; Fig. 7B) and promoted EMT progress $(\mathrm{P}<0.05$; Fig. $7 \mathrm{E})$. Similarly, FAK knockdown by a specific siRNA in miR-379-suppressive SGC7901 cells $(\mathrm{P}<0.05$; Fig. 7C) significantly inhibited cell migration, invasion $(\mathrm{P}<0.05$, respectively; Fig. 7D) and EMT progress $(\mathrm{P}<0.05$; Fig. $7 \mathrm{~F})$. These data demonstrated that FAK is a downstream mediator in the function of miR-379 in GC. 
A
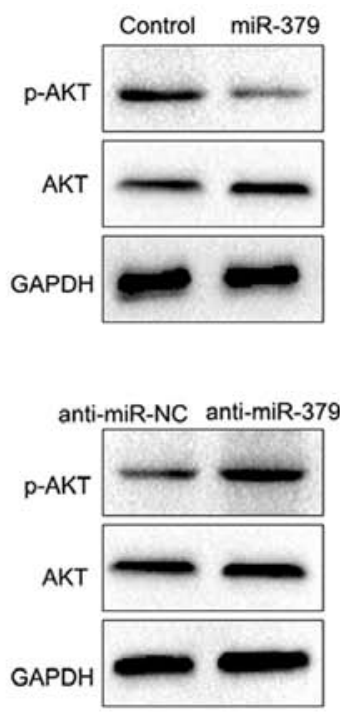
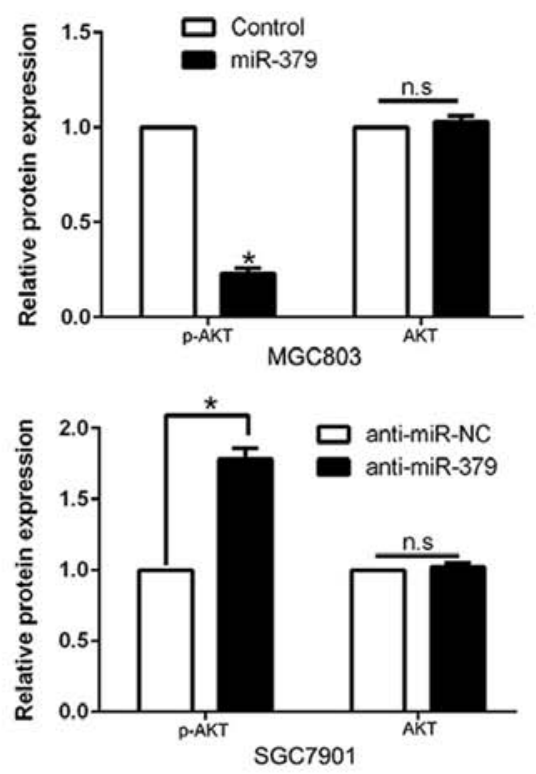
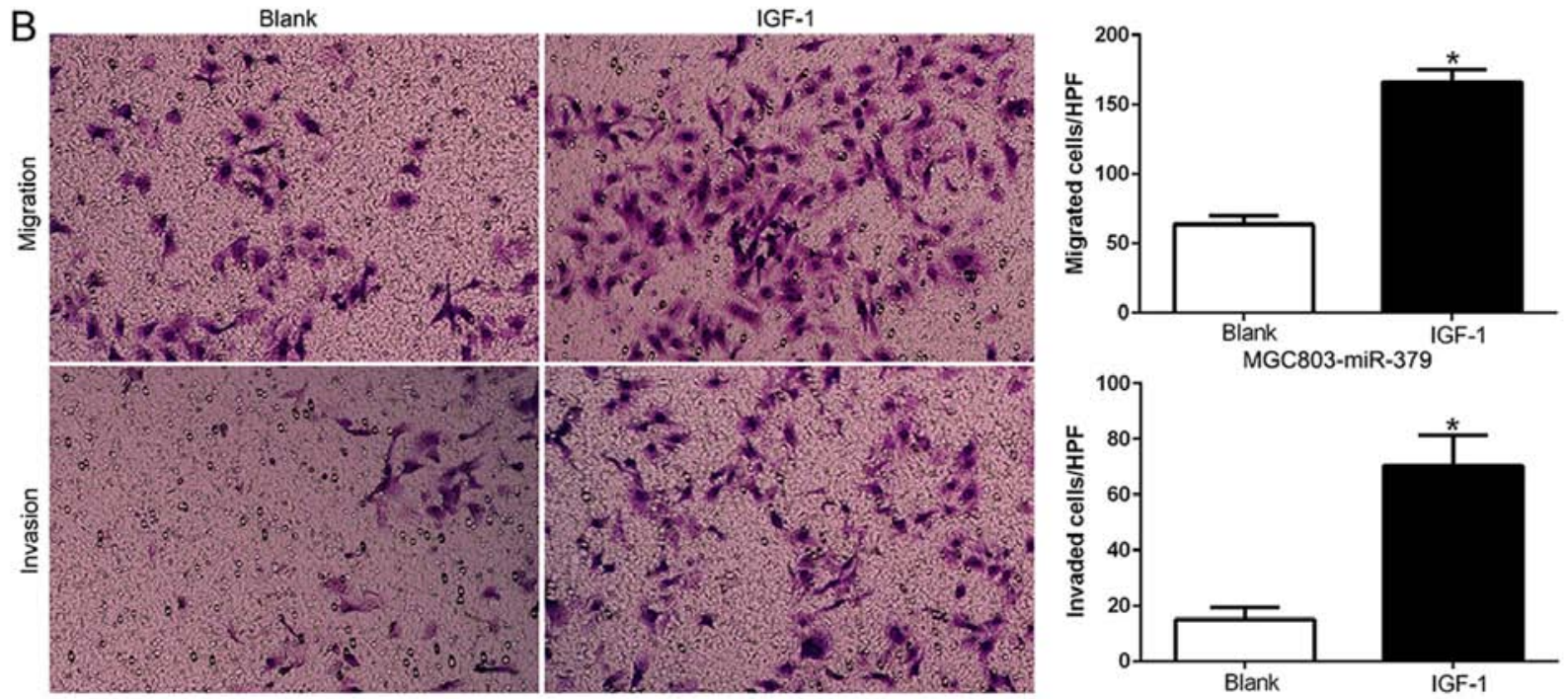

Figure 8. PI3K/AKT signaling is essential for the biological function of miR-379 in GC. (A) Western blot analysis of AKT and phosphorylated AKT in MGC803-miR-379 or SGC7901-anti-miR-379 cells. (B) Quantification of migration and invasion of MGC803-miR-379 treated with $100 \mathrm{ng} / \mathrm{ml}$ IGF-1 for $24 \mathrm{~h}$.

PI3K/AKT signaling is essential for the biological function of miR-379 in GC. Previous studies demonstrated that FAK could induce the activation of PI3K/AKT signaling and play a critical role in the invasion and metastasis of GC and EMT $(27,28)$. As shown in Fig. 8A, ectopic expression of miR-379 significantly decreased, while miR-379 knockdown increased the AKT phosphorylation in GC cells $(\mathrm{P}<0.05$; Fig. 8A). However, the total AKT protein had no change $(\mathrm{P}<0.05$; Fig. $8 \mathrm{~A})$. These data indicate that miR-379 suppressed the PI3K/AKT pathway in GC cells. To determine whether AKT phosphorylation mediated miR-379-induced inhibition of cell migration, invasion and EMT process in GC cells, we treated miR-379-overexpressing MGC803 cells with insulin-like growth factor 1 (IGF-1), which is an activator of PI3K/AKT pathway. We found that IGF-1 at least partially rescued the miR-379-induced inhibition of cell migration, invasion $(\mathrm{P}<0.05$; Fig. 8B $)$ and EMT process $(\mathrm{P}<0.05$; Fig. 8D). Conversely, the restraint of the PI3K/AKT pathway by MK2206 abrogated the effects of miR-379 inhibition to induce cell migration, invasion $(\mathrm{P}<0.05$; Fig. $8 \mathrm{C})$ and EMT progress $(\mathrm{P}<0.05$; Fig. 8D) in miR-379-suppressive SGC7901 cells. Taken together, our results demonstrate that PI3K/AKT signaling plays an essential function during miR-379-induced GC cell migration, invasion and EMT progression

\section{Discussion}

Systemic metastasis of GC is the major cause of the tumor recurrence and patient mortality. Increasing evidence has demonstrated that miRNAs were involved in GC invasion and metastasis $(29,30)$. Therefore, miRNAs have been regarded as potential biomarkers and therapeutic targets for GC. In previous studies, Chen et al (16) demonstrated that microRNA-379-5p inhibited tumor invasion and metastasis by targeting FAK/AKT signaling in hepatocellular carcinoma (HCC), moreover, miR-379 suppressed HCC metastasis and EMT in vivo. In addition, Khan et al (12) confirmed that miR-379 was decreased in breast cancer and could be a novel 

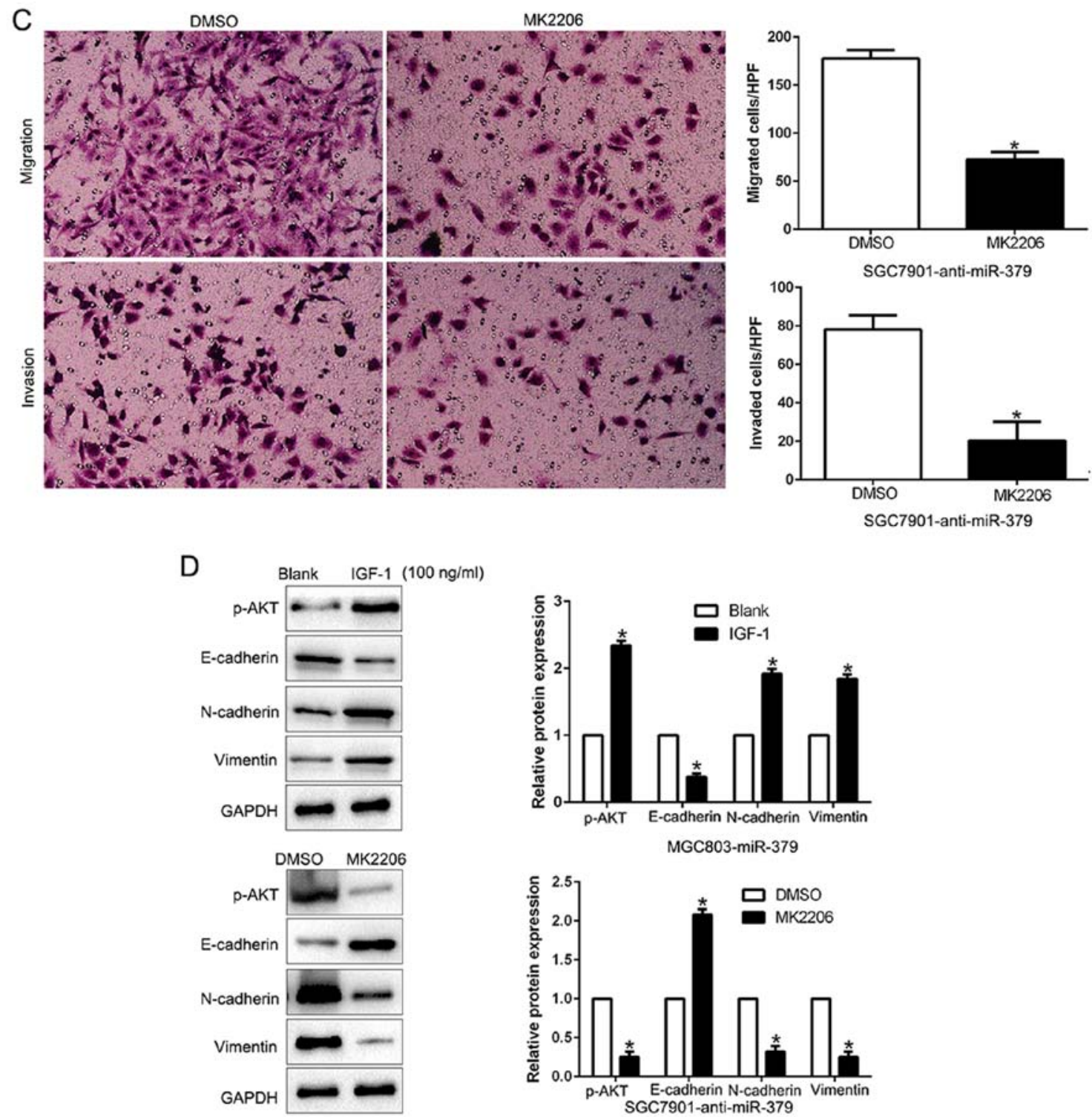

Figure 8. Continued. (C) Quantification of migration and invasion of SGC7901 cells stably expressing miR-379 inhibitor treated with $1 \mu \mathrm{M}$ MK2206 for $24 \mathrm{~h}$ (D) Western blot analysis of indicated proteins in MGC803 cells stably expressing miR-379 treated for $24 \mathrm{~h}$ with $100 \mathrm{ng} / \mathrm{ml}$ IGF-1 or SGC7901 cells stably expressing miR-379 inhibitor treated with $1 \mu \mathrm{M}$ MK2206 for $24 \mathrm{~h} .{ }^{*} \mathrm{P}<0.05$.

regulator of cyclin B1. However, on the contrary, miR-379 in the DLK1-DIO3 miRNA mega-cluster regulated EMT and bone metastasis of prostate cancer (13). Moreover, miR-379 was downregulated in papillary renal cell carcinoma and significantly associated with patient survival (18). These data indicated that the expression level and biological effect was dependent on the cancer type.

In the present study, we found that miR-379 was significantly downregulated in $96 \mathrm{GC}$ tissues compared with the corresponding non-cancerous tissues. Similarly, the expression level of miR-379 in gastric cancer cell lines were significantly decreased. Reduced miR-379 expression was obviously correlated with malignant clinicopathological characteristics of GC patients, including advanced TNM stage and lymph node metastasis. Moreover, we found that low miR-379 group had a significantly worse 5-year OS and PFS for GC patients. Multivariate Cox repression analysis indicated that miR-379 was an independent prognostic factor for predicting survival of
GC patients. Taken together, these results suggest that miR-379 is critical for prognosis outcome of GC patients. Importantly, gain- and loss-function experiment demonstrated that miR-379 inhibited cell migration, invasion and EMT, at least partially by targeting FAK mediated PI3K/AKT signaling pathway. Furthermore, miR-379 was inversely correlated with FAK expression, which was elevated in GC tissues (31). In addition, miR-379 could negatively modulate FAK accumulation in GC cells. Taken together, these results demonstrated that miR-379 functions as a tumor suppressor in the migration, invasion and EMT of GC by directly inhibiting FAK/AKT pathway.

FAK, a non-receptor tyrosine kinase, plays a critical role in integrin signaling and promotes cancer progression, invasion and metastasis (32). Increased FAK expression was positively associated with poor survival and cancer progression in different cancers, including GC (33). FAK/PI3K/AKT signaling was found to promote EMT progression, which was proposed as a vital mechanism that regulates the initial steps of 
metastatic progression of cancer (34). Our results showed that AKT pathway abolished the inhibitory or stimulatory effect of miR-379 on GC cells. Taken together, these data demonstrated the suppressive effect of miR-379 was mediated by targeting FAK to inhibit AKT phosphorylation pathway in GC.

In summary, we demonstrated that miR-379 was downregulated in GC tissues and cell lines, and its decreased expression was correlated with malignant clinicopathological features. Furthermore, we confirmed that miR-379 inhibited cell migration, invasion and EMT by inhibiting FAK mediated PI3K/AKT signaling pathway. These results suggest that miR-379 is a potential metastasis-associated tumor suppressor in GC. Collectively, the deregulation of miR-379 may play an important role in tumor metastasis and may be a novel prognostic factor and potential therapeutic target for GC.

\section{References}

1. Siegel RL, Miller KD and Jemal A: Cancer statistics, 2015. CA Cancer J Clin 65: 5-29, 2015

2. Ferlay J, Soerjomataram I, Dikshit R, Eser S, Mathers C, Rebelo M, Parkin DM, Forman D and Bray F: Cancer incidence and mortality worldwide: Sources, methods and major patterns in GLOBOCAN 2012. Int J Cancer 136: E359-E386, 2015.

3. De Vita F, Vecchione L, Galizia G, Di Martino N, Fabozzi T, Catalano G, Ciardiello F and Orditura M: Perspectives in adjuvant therapy of gastric cancer. Oncology 77 (Suppl 1): 38-42, 2009.

4. Kagawa S, Shigeyasu K, Ishida M, Watanabe M, Tazawa H, Nagasaka T, Shirakawa Y and Fujiwara T: Molecular diagnosis and therapy for occult peritoneal metastasis in gastric cancer patients. World J Gastroenterol 20: 17796-17803, 2014.

5. Bessette DC, Qiu D and Pallen CJ: PRL PTPs: Mediators and markers of cancer progression. Cancer Metastasis Rev 27: 231-252, 2008

6. Alvarez-Garcia I and Miska EA: MicroRNA functions in animal development and human disease. Development 132: 4653-4662, 2005.

7. Calin GA and Croce CM: MicroRNA-cancer connection: The beginning of a new tale. Cancer Res 66: 7390-7394, 2006.

8. LiC, Song L, Zhang Z, Bai XX, Cui MF and Ma LJ: MicroRNA-21 promotes TGF- $\beta 1$-induced epithelial-mesenchymal transition in gastric cancer through up-regulating PTEN expression. Oncotarget 7: 66989-67003, 2016.

9. Zheng L, Jiao W, Mei H, Song H, Li D, Xiang X, Chen Y, Yang F, Li H, Huang K, et al: miRNA-337-3p inhibits gastric cancer progression through repressing myeloid zinc finger 1-facilitated expression of matrix metalloproteinase 14. Oncotarget 7: 40314-40328, 2016.

10. Zhang PF, Sheng LL, Wang G, Tian M, Zhu LY, Zhang R, Zhang $J$ and Zhu JS: miR-363 promotes proliferation and chemo-resistance of human gastric cancer via targeting of FBW7 ubiquitin ligase expression. Oncotarget 7: 35284-35292, 2016.

11. Bartels CL and Tsongalis GJ: MicroRNAs: Novel biomarkers for human cancer. Clin Chem 55: 623-631, 2009.

12. Khan S, Brougham CL, Ryan J, Sahrudin A, O'Neill G, Wall D, Curran C, Newell J, Kerin MJ and Dwyer RM: miR-379 regulates cyclin B1 expression and is decreased in breast cancer. PLoS One 8: e68753, 2013

13. Gururajan M, Josson S, Chu GC, Lu CL, Lu YT, Haga CL, Zhau HE, Liu C, Lichterman J, Duan P, et al: miR-154* and miR-379 in the DLK1-DIO3 microRNA mega-cluster regulate epithelial to mesenchymal transition and bone metastasis of prostate cancer. Clin Cancer Res 20: 6559-6569, 2014.

14. Pollari S, Leivonen SK, Perälä M, Fey V, Käkönen SM and Kallioniemi O: Identification of microRNAs inhibiting TGF- $\beta$ induced IL-11 production in bone metastatic breast cancer cells. PLoS One 7: e37361, 2012.

15. Skalsky RL and Cullen BR: Reduced expression of brain-enriched microRNAs in glioblastomas permits targeted regulation of a cell death gene. PLoS One 6: e24248, 2011.
16. Chen JS, Li HS, Huang JQ, Dong SH, Huang ZJ, Yi W, Zhan GF, Feng JT, Sun JC and Huang XH: MicroRNA-379-5p inhibits tumor invasion and metastasis by targeting FAK/AKT signaling in hepatocellular carcinoma. Cancer Lett 375: 73-83, 2016.

17. Yamamoto K, Seike M, Takeuchi S, Soeno C, Miyanaga A, Noro R, Minegishi Y, Kubota K and Gemma A: MiR-379/411 cluster regulates IL-18 and contributes to drug resistance in malignant pleural mesothelioma. Oncol Rep 32: 2365-2372, 2014.

18. Ge YZ, Xu LW, Xu Z, Wu R, Xin H, Zhu M, Lu TZ, Geng LG, Liu H, Zhou CC, et al: Expression profiles and clinical significance of MicroRNAs in papillary renal cell carcinoma: A STROBE-Compliant Observational Study. Medicine (Baltimore) 94: e767, 2015.

19. Thiery JP, Acloque H, Huang RY and Nieto MA: Epithelialmesenchymal transitions in development and disease. Cell 139: 871-890, 2009.

20. Zheng $\mathrm{H}$ and Kang Y: Multilayer control of the EMT master regulators. Oncogene 33: 1755-1763, 2014.

21. Duan F, Jia D, Zhao J, Wu W, Min L, Song S, Wu H, Wang L, Wang H, Ruan Y, et al: Loss of GFAT1 promotes epithelial-tomesenchymal transition and predicts unfavorable prognosis in gastric cancer. Oncotarget 7: 38427-38439, 2016.

22. Lee J, Ha S, Jung CK and Lee HH: High-mobility-group A2 overexpression provokes a poor prognosis of gastric cancer through the epithelial-mesenchymal transition. Int J Oncol 46: 2431-2438, 2015.

23. Yan Y, Zhang J, Li JH, Liu X, Wang JZ, Qu HY, Wang JS and Duan XY: High tumor-associated macrophages infiltration is associated with poor prognosis and may contribute to the phenomenon of epithelial-mesenchymal transition in gastric cancer. Onco Targets Ther 9: 3975-3983, 2016.

24. Hu J, Shan Z, Hu K, Ren F, Zhang W, Han M, Li Y, Feng K, Lei L and Feng Y: miRNA-223 inhibits epithelial-mesenchymal transition in gastric carcinoma cells via Sp1. Int J Oncol 49: 325-335, 2016.

25. Wang LL, Zhang XH, Zhang X and Chu JK: MiR-30a increases cisplatin sensitivity of gastric cancer cells through suppressing epithelial-to-mesenchymal transition (EMT). Eur Rev Med Pharmacol Sci 20: 1733-1739, 2016.

26. Zhang LL, Liu J, Lei S, Zhang J, Zhou W and Yu HG: PTEN inhibits the invasion and metastasis of gastric cancer via downregulation of FAK expression. Cell Signal 26: 1011-1020, 2014.

27. Zhang PF, Li KS, Shen YH, Gao PT, Dong ZR, Cai JB, Zhang C, Huang XY, Tian MX, Hu ZQ, et al: Galectin-1 induces hepatocellular carcinoma EMT and sorafenib resistance by activating FAK/PI3K/AKT signaling. Cell Death Dis 7: e2201, 2016.

28. Feng $\mathrm{R}$ and Yang S: Effects of combining erlotinib and RNA-interfered downregulation of focal adhesion kinase expression on gastric cancer. J Int Med Res 44: 855-864, 2016

29. Chen P, Zhao H, Huang J, Yan X, Zhang Y and Gao Y: MicroRNA$17-5 \mathrm{p}$ promotes gastric cancer proliferation, migration and invasion by directly targeting early growth response 2 . Am J Cancer Res 6: 2010-2020, 2016.

30. Sun J, Li J, Zhang W, Zhang J, Sun S, Li G, Song H and Wan D: MicroRNA-509-3p inhibits cancer cell proliferation and migration via upregulation of XIAP in gastric cancer cells. Oncol Res 25: 455-461, 2016.

31. Park JH, Lee BL, Yoon J, Kim J, Kim MA, Yang HK and Kim WH: Focal adhesion kinase (FAK) gene amplification and its clinical implications in gastric cancer. Hum Pathol 41: 1664-1673, 2010.

32. Zhou Y, Dang J, Chang KY, Yau E, Aza-Blanc P, Moscat J and Rana TM: miR-1298 inhibits mutant KRAS-driven tumor growth by repressing FAK and LAMB3. Cancer Res 76: 5777-5787, 2016.

33. Guo LL, He ZC, Yang CQ, Qiao PT and Yin GL: Epigenetic silencing of olfactomedin-4 enhances gastric cancer cell invasion via activation of focal adhesion kinase signaling. BMB Rep 48: 630-635, 2015.

34. Song G, Xu S, Zhang H, Wang Y, Xiao C, Jiang T, Wu L, Zhang T, Sun X, Zhong L, et al: TIMP1 is a prognostic marker for the progression and metastasis of colon cancer through FAK-PI3K/ AKT and MAPK pathway. J Exp Clin Cancer Res 35: 148, 2016. 